\title{
Removal of Radionuclide Uranium from South China's Ion-adsorption Rare Earth Leach Liquor Using Solvent Extraction with Naphthenic Acid
}

\author{
Kuifang ZHANG ${ }^{1,3,4}$, Yuping ZENG ${ }^{2}$, Zhiqiang LIU ${ }^{1,3,4 *}$, Hongyang CAO ${ }^{1,3,4}$, \\ Wei ZHU ${ }^{1,3,4}$ and Qiusong GUO ${ }^{1,3,4}$ \\ ${ }^{1}$ Guangdong Research Institute of Rare Metals, Guangzhou 510650, China; ${ }^{2}$ Department of Radiology, \\ Guangzhou Universal Medical Imaging Diagnostic Center, Guangzhou 510080, China; ${ }^{3}$ Guangdong \\ Province Key Laboratory of Rare Earth Development and Application, Guangzhou 510650, China; ${ }^{4}$ State \\ Key Laboratory of Separation and Comprehensive Utilization of Rare Metals, Guangzhou 510650, China
}

(Received January 23, 2019; Accepted April 22, 2019)

A novel naphthenic acid extractant has been used to remove U from South China's ion-adsorption rare earth (RE) leach liquor. The system was optimized in terms of its extractant composition and the conditions for loading, stripping and phase separation. Extraction and stripping distribution isotherms were determined. $99.70 \%$ of the $U$ was removed by three-stage counter current extraction using $15 \%(\mathrm{v} / \mathrm{v})$ naphthenic acid and $15 \%(\mathrm{v} / \mathrm{v})$ iso-octanol in sulfonated kerosene with an $\mathrm{A} / \mathrm{O}$ ratio of $1: 1$ at $27 \pm 1{ }^{\circ} \mathrm{C}$, while $67.50 \%$ of the $\mathrm{Fe}, 16.53 \%$ of the Al, but only $1.71 \%$ of the RE were co-extracted, resulting in the separation of $\mathrm{U}$ from RE. The loaded metals could be completely removed by three-stage counter current stripping with $5 \mathrm{~mol} / \mathrm{L} \mathrm{HCl}$ with an $\mathrm{A} / \mathrm{O}$ ratio of $1: 10$ at $27 \pm 1{ }^{\circ} \mathrm{C}$, allowing the extractant to be regenerated and recycled. The U--enriched strip liquor contained $164.50 \mathrm{mg} / \mathrm{L}$, facilitating the subsequent precipitation of radioactive pollutants.

\section{Introduction}

South China's ion-adsorption RE are rare and precious mineral resources for the RE industry in China. In recent years, with the rigid requirements for cleaner processing of RE resources, the presence of the trace radionuclide $U$ has caused concern and received lots of attention. During the separation processing of South China's ion-adsorption RE, $\mathrm{U}$ is leached together with RE and after the multistage extraction and separation process of RE, $\mathrm{U}$ reports to the RE oxide products and production wastewater. As a result, the radioactivity levels of RE oxide products and wastewater seriously exceed the standards needed for cleaner production and for the quality of RE oxide products. There is a pressing need to remove $\mathrm{U}$ from the leach liquor before the multistage RE separation processes.

Traditional separation methods for $U$ and RE include neutralization precipitation [1-2], double sulfate precipitation [3-5] and oxalate precipitation [6]. Because the precipitation $\mathrm{pH}$ 's of $\mathrm{U}$ and $\mathrm{RE}$ are similar, neutralization precipitation gives poor selectivity for U over RE. Double sulfate precipitation and oxalate precipitation have been shown to be effective in separating $U$ from RE, but the separation is achieved by precipitating the RE's rather than the U. Other techniques, such as adsorption by various materials [7-10], are effective in some applications, but high cost and tightly controlled conditions have limited their usefulness in industrial practice.

The preferred separation method is solvent extraction of $U$ [11]. Extractants include amines such as 
N1923, N235 and Alamine 336 [12-14], neutral organophosphorus reagents such as TBP, DMHMP and Cyanex923 [15-17] and acidic organophosphorus reagents such as Cyanex272, EHEHPA and D2EHPA [18-20]. Only in sulphate solutions can amine extractants exhibit a good performance for the extraction of $\mathrm{U}$ [13]. The presence of chloride in the leach liquor has a negative impact on the solvent extraction process. Neutral organophosphorus extractants can be used to separate $U$ from RE only from high concentration nitrate and chloride media [17]. These demanding conditions for the use of amine or neutral organophosphorus extractants have greatly limited their application. Acidic organophosphorus extractants strongly extract $U$ either in highly or moderately acidic sulphate and chloride media. However, the U-stripping is difficult [21-23]. This paper describes the use of a novel naphthenic acid extractant for the separation of U from South China's ion-adsorption RE leach liquor and explores its potential in industrial applications.

\section{Experimental}

\subsection{Materials}

The naphthenic acid (Technical grade, purity $>98 \%$ ) was provided by Shenyang Chemical Co., Ltd. As sulfonated kerosene is the commonly used diluent in the South China's ion-adsorption RE plants, it was also selected (Technical grade) for the work described this paper. The modifier iso-octanol (Chemically Pure) was provided by Shanghai Laiyashi Chemical Company. Hydrochloric acid (Analytical reagent) and sodium hydroxide (Analytical reagent) were provided by Nanjing Chemical Reagent Company. All reagents were used as received. The naphthenic acid reagent is a mixture of different cycloalkyl carboxylic acids (see Figure 1). The composition of South China's ion-adsorption RE leach

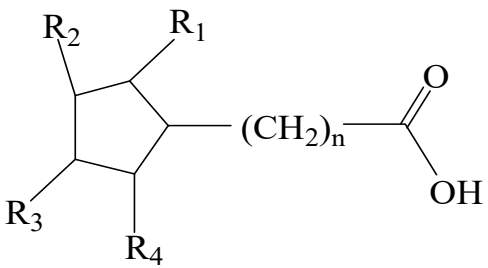

where, $\mathrm{R}_{1}, \mathrm{R}_{2}, \mathrm{R}_{3}, \mathrm{R}_{4}=$ different alkyls or $\mathrm{H}$

Figure 1. Structure of active component of naphthenic acid. liquor is shown in Table 1.

Table 1. The concentrations of RE and U in South China's ion-adsorption RE leach liquor.

\begin{tabular}{cccccc}
\hline Element & $\mathrm{RE}$ & $\mathrm{U}$ & $\mathrm{Fe}$ & $\mathrm{Al}$ & $\mathrm{pH}$ \\
\hline Concentration & $1.75 \mathrm{~mol} / \mathrm{L}$ & $16.50 \mathrm{mg} / \mathrm{L}$ & $28.00 \mathrm{mg} / \mathrm{L}$ & $2.36 \mathrm{~g} / \mathrm{L}$ & 2.45 \\
\hline
\end{tabular}

\subsection{Methods}

The single-stage extraction and stripping experiments were carried out in a $125 \mathrm{~mL}$ separating funnel (provided from Beijing BOMEX Glass Company) immersed in a constant temperature oscillator (provided from Jiangsu Maipulong Instrument Manufacturing Company). The aqueous $\mathrm{pH}$ was measured using a Metrohm 826 mobile $\mathrm{pH}$ meter with $\mathrm{Ag} / \mathrm{AgCl}$ internal micro-electrode and was adjusted as required with the addition of hydrochloric acid or sodium hydroxide solution. To determine the extraction distribution isotherms, the organic system was contacted with leaching liquor at $\mathrm{A} / \mathrm{O}$ ratios of 1:2, 1:1, 2:1, and 3:1. To determine the stripping distribution isotherms, the loaded organic system was contacted with strip solution at $\mathrm{A} / \mathrm{O}$ ratios of $1: 1,1: 5,1: 10$, and 1:15. The multistage counter current extraction and stripping tests were performed and simulated in a multi-stage mixer-settlers system. The mixer-settlers, peristaltic pumps, and 
other auxiliary equipment were provided by Beijing Institute of Extractive Applied Technology. All experiments were performed at the laboratory temperature $\left(27 \pm 1^{\circ} \mathrm{C}\right)$. Samples were collected and analyzed to determine the concentrations of metals. The concentrations of RE in aqueous samples was determined by complexometric titration with EDTA and the concentrations of U ICP-MS (Perkin-Elmer Elan 9000). The metal concentration of loaded organic solutions were calculated by difference:

$$
\text { Percentage extraction }(\% \mathrm{E}): \quad \% \mathrm{E}=\frac{[\mathrm{M}] \text { aq.in }-[\mathrm{M}] \text { aq.eq }}{[\mathrm{M}] \text { aq.in }} \times 100
$$

where, $[\mathrm{M}]$ aq.in = initial $[\mathrm{M}]$ concentration in the aqueous phase before each extraction stage and $[\mathrm{M}] \mathrm{aq}, \mathrm{eq}=[\mathrm{M}]$ concentration in the aqueous phase after each extraction stage. $[\mathrm{M}]$ can be RE, $\mathrm{U}, \mathrm{Fe}$ and Al.

Percent stripping $(\% \mathrm{~S}): \quad \% \mathrm{~S}=\frac{[\mathrm{M}] \text { org.in }-[\mathrm{M}] \text { org, eq }}{[\mathrm{M}] \text { org } \cdot \text { in }} \times 100$

where, $[\mathrm{M}]$ org.in $=$ initial $[\mathrm{M}]$ concentration in the organic phase before each stripping stage and $[\mathrm{M}]$ org,eq $=[\mathrm{M}]$ concentration in the organic phase after each stripping stage. $[\mathrm{M}]$ can be RE, U, Fe and Al.

\section{Results and discussion}

\subsection{Extraction}

\subsubsection{Effect of the naphthenic acid concentrations on the extraction}

Effects of the naphthenic acid concentration in the range of $5 \%$ to $20 \%(\mathrm{v} / \mathrm{v})$ in a sulfonated kerosene on the extraction were investigated and the results are shown in Figure 2 and Table 2. The extractant solution was contacted with leach liquor at an $\mathrm{A} / \mathrm{O}$ ratio of $1: 1$ at $27 \pm 1^{\circ} \mathrm{C}$ for $10 \mathrm{~min}$.

It can be seen from Figure 2 that the extraction of $U$ increases sharply from 47 to $93 \%$ with the increase of naphthenic acid concentration from 5 to $20 \%(\mathrm{v} / \mathrm{v})$, while the extraction of RE remains negligible. Table 2 shows that the phase separation time increases markedly with the increase of concentration of the naphthenic acid. At above $15 \%$ of naphthenic acid an emulsion is formed This can be attributed to the self-polymerization of naphthenic acid in the non-polar sulfonated kerosene solvent [24]. Based on the U--loading levels and phase separatio characteristics, a naphthenic acid concentration of $15 \%(\mathrm{v} / \mathrm{v})$ was selected for further work using the modifier iso-octanol to improve phase separation (see below).

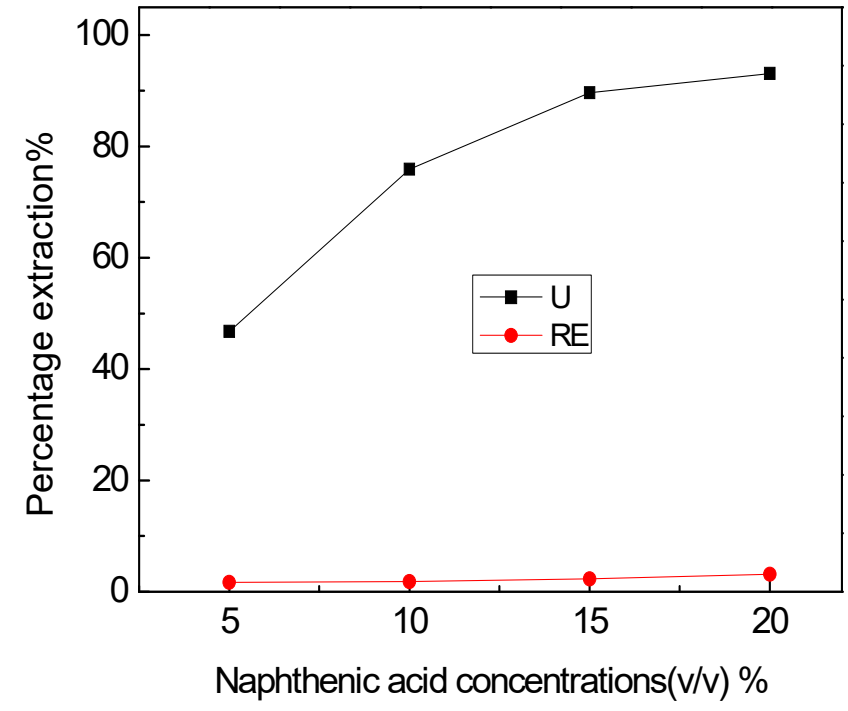

Figure 2. Effect of the naphthenic acid concentrations on the extraction. 
Table 2. Effect of naphthenic acid concentration on phase separation.

\begin{tabular}{ccccc}
\hline $\begin{array}{c}\text { Naphthenic acid } \\
\text { concentrations (v/v)\% }\end{array}$ & $5 \%$ & $10 \%$ & $15 \%$ & $20 \%$ \\
\hline Phase separation & $\begin{array}{c}3 \text { min, } \\
\text { without emulsion }\end{array}$ & $\begin{array}{c}8 \mathrm{~min}, \\
\text { without emulsion }\end{array}$ & $\begin{array}{c}23 \mathrm{~min}, \\
\text { slight emulsion }\end{array}$ & $\begin{array}{c}36 \text { min, } \\
\text { moderate emulsion }\end{array}$ \\
\hline
\end{tabular}

\subsubsection{Effect of the modifier, iso-octanol, concentrations on the extraction}

The effect of iso-octanol concentration in the range of 5 to $20 \%(\mathrm{v} / \mathrm{v})$ on the extraction was investigated. An organic system which consisted of $15 \%(\mathrm{v} / \mathrm{v})$ naphthenic acid, 5 to $20 \%(\mathrm{v} / \mathrm{v})$ iso-octanol and 65 to $80 \%(\mathrm{v} / \mathrm{v})$ sulfonated kerosene was contacted with leach liquor at an $\mathrm{A} / \mathrm{O}$ ratio of $1: 1$ at $27 \pm 1^{\circ} \mathrm{C}$ for $10 \mathrm{~min}$. It can be seen in Table 3 and Figure 3 that the phase separation was not only significantly improved by the addition of iso-octanol, but the extraction of $U$ also increased from 89 to $98 \%$ with the increase of iso-octanol concentration from 5 to $20 \%$ $(\mathrm{v} / \mathrm{v})$, while RE extraction was still negligible. The addition of $15 \%(\mathrm{v} / \mathrm{v})$ or more iso-octanol ensures a good phase separation and $\mathrm{U}$ extraction. Consequently, an extractant composition of $15 \%(\mathrm{v} / \mathrm{v})$ naphthenic acid and $15 \%(\mathrm{v} / \mathrm{v})$ iso-octanol in sulfonated kerosene was used in further work. It can be assumed that the addition of the polar solvent iso-octanol reduces the self-polymerization of naphthenic acid, making more monomers available for binding to $U$.

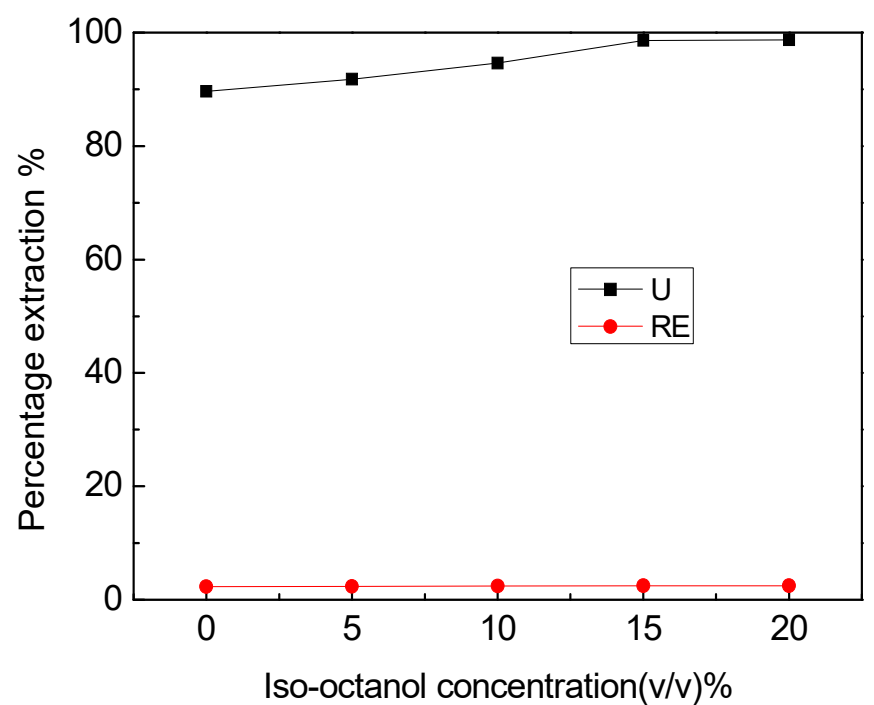

Figure 3. Effect of the modifier iso-octanol concentrations on the extraction.

Table 3. Effects of the iso-octanol concentrations on the phase separation.

\begin{tabular}{ccccc}
\hline $\begin{array}{c}\text { Isooctanol } \\
\text { concentrations (v/v)\% }\end{array}$ & $5 \%$ & $10 \%$ & $15 \%$ & $20 \%$ \\
\hline Phase separation & $\begin{array}{c}20 \mathrm{~min}, \\
\text { slight emulsion }\end{array}$ & $\begin{array}{c}18 \mathrm{~min}, \\
\text { without emulsion }\end{array}$ & $\begin{array}{c}13 \mathrm{~min}, \\
\text { without emulsion }\end{array}$ & $\begin{array}{c}13 \mathrm{~min}, \\
\text { without emulsion }\end{array}$ \\
\hline
\end{tabular}

\subsubsection{Effect of acidity on the extraction}

The dependence of U--loading on the $\mathrm{pH}$ of the leach liquor in the range -0.25 to 3.0 was investigated as follows. To $80 \mathrm{ml}$ portions of the leach liquor were added aqueous hydrochloric acid or sodium hydroxide (volumes $<20 \mathrm{ml}$ ) to give $\mathrm{pH}$ values in the ranged -0.25 to 3.0. Volumes were then made up to $100 \mathrm{ml}$ and $\mathrm{pH}$ values were recorded. The organic phase consisted of $15 \%(\mathrm{v} / \mathrm{v})$ naphthenic acid and $15 \%(\mathrm{v} / \mathrm{v})$ iso-octanol in sulfonated kerosene. After contacting with an equal volume of each portion of 
leach liquor at $27 \pm 1^{\circ} \mathrm{C}$ for $10 \mathrm{~min}$, their $\mathrm{pH}$ values were recorded $(-0.22,0.47,0.97,1.52,2.05,2.55$, and 3.04), see Figure 4.

Figure 4 shows that extraction of $\mathrm{U}$ increases sharply from 46 to $97 \%$ as the $\mathrm{pH}$ of the leach liquor is increased from -0.25 to 1.0 , and then levels off in the range 1.0 to 3.0. The extraction of $\mathrm{RE}$ remains negligible over the $\mathrm{pH}$ range tested. As the $\mathrm{pH}$ of South China's ion-adsorption RE leach liquor always falls in the range 1.0 to 3.0 , no $\mathrm{pH}$ adjustment will be needed in a commercial operation.

\subsubsection{Effect of the contact time on extraction}

The effects of the variation of contact time from 2 to $20 \mathrm{~min}$ metal loadings by a solution of $15 \%(\mathrm{v} / \mathrm{v})$ naphthenic acid and $15 \%(\mathrm{v} / \mathrm{v})$ iso-octanol in sulfonated kerosene at an $\mathrm{A} / \mathrm{O}$ ratio of $1: 1$ at $27 \pm 1^{\circ} \mathrm{C}$ are shown in Figure 5 . More than $80 \%$ of the $\mathrm{U}$ was extracted within $2 \mathrm{~min}$ and equilibrium is reached within $5 \mathrm{~min}$, indicating reasonably fast extraction kinetics. A contact time of 5 min was selected for further tests.

\subsubsection{Effect of the temperature on the} extraction

The effect of raising the temperature from 15 to $45{ }^{\circ} \mathrm{C}$ on extractions using a $10 \mathrm{~min}$ contact time is shown in Table 4 and Figure 6. Both the loadings of $U$ and RE show only a small

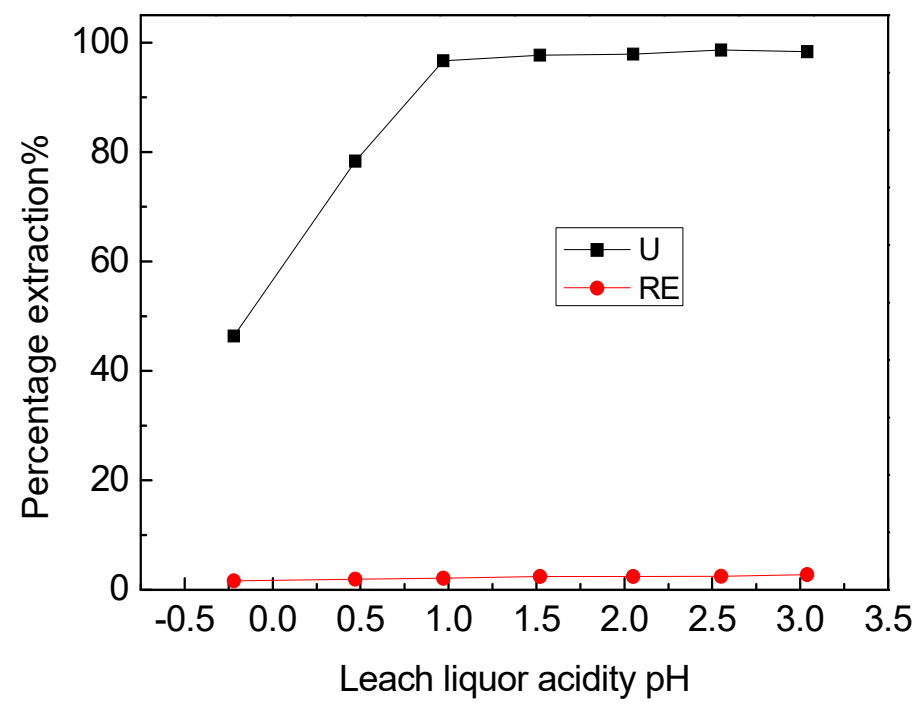

Figure 4. Effect of the leach liquor acidity on the extraction

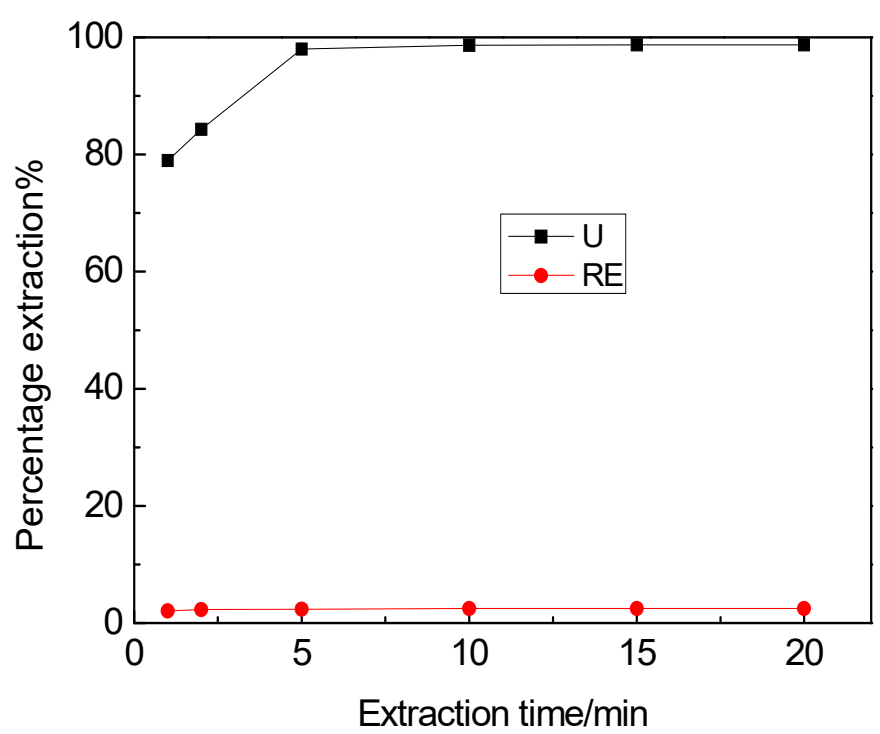

Figure 5. Effect of the extraction time on the extraction dependence on temperature in the range 15 to $45{ }^{\circ} \mathrm{C}$. However, the phase separation time is significantly shorter at higher temperatures. This could be attributed to the organic phase having a lower viscosity.To ensure more rapid phase separation rates the operating temperature should be $>25{ }^{\circ} \mathrm{C}$, and consequentlywas set at $27 \pm 1^{\circ} \mathrm{C}$ for the work in this paper.

Table 4. Effects of the temperature on the phase separation.

\begin{tabular}{ccccc}
\hline Temperatures & $15^{\circ} \mathrm{C}$ & $25^{\circ} \mathrm{C}$ & $35^{\circ} \mathrm{C}$ & $45^{\circ} \mathrm{C}$ \\
\hline Phase separation & $21 \mathrm{~min}$ & $13 \mathrm{~min}$ & $12.5 \mathrm{~min}$ & $10 \mathrm{~min}$ \\
\hline
\end{tabular}




\subsection{6 $\mathrm{U}$ extraction isotherms and McCabe-Thiele diagram}

The $U$ extraction isotherm was determined using the reagent composition and aqueous feed solution described above with $\mathrm{A} / \mathrm{O}$ ratios of 1:2, 1:1, 2:1, 3:1 at $27 \pm 1^{\circ} \mathrm{C}$ with a contact time of $5 \mathrm{~min}$. It can be seen from Figure 7 that the $\mathrm{U}$ extraction capacity was ca. $25 \mathrm{mg} / \mathrm{L}$. To ensure that $U$ would be completely extracted, an $\mathrm{A} / \mathrm{O}$ ratio of $1: 1$ was selected for counter current extraction experiments. Based on the McCabe-Thiele diagram, two extraction stages were needed to recover almost all of the $\mathrm{U}$, leaving only a few $\mathrm{mg} / \mathrm{L}$ of $\mathrm{U}$ in the raffinate. Assuming that the stage efficiency cannot be $100 \%$, a three-stage counter current extraction system was chosen for the tests described below.

\subsubsection{Three-stage counter current extraction test}

Results of a three-stage counter current extraction test conducted using the reagent, feed and conditions described above are shown in Table 5. $99.70 \% \mathrm{U}, 67.50 \% \mathrm{Fe}$, and $16.53 \% \mathrm{Al}$, were extracted but only $1.71 \% \mathrm{RE}$, indicating that $\mathrm{U}$ can be separated from $\mathrm{RE}$ in the South China's ion-adsorption RE leach liquor with high selectivity. The concentration of $U$ in loaded organic solutions, calculated by the subtraction method was $16.45 \mathrm{mg} / \mathrm{L}$.

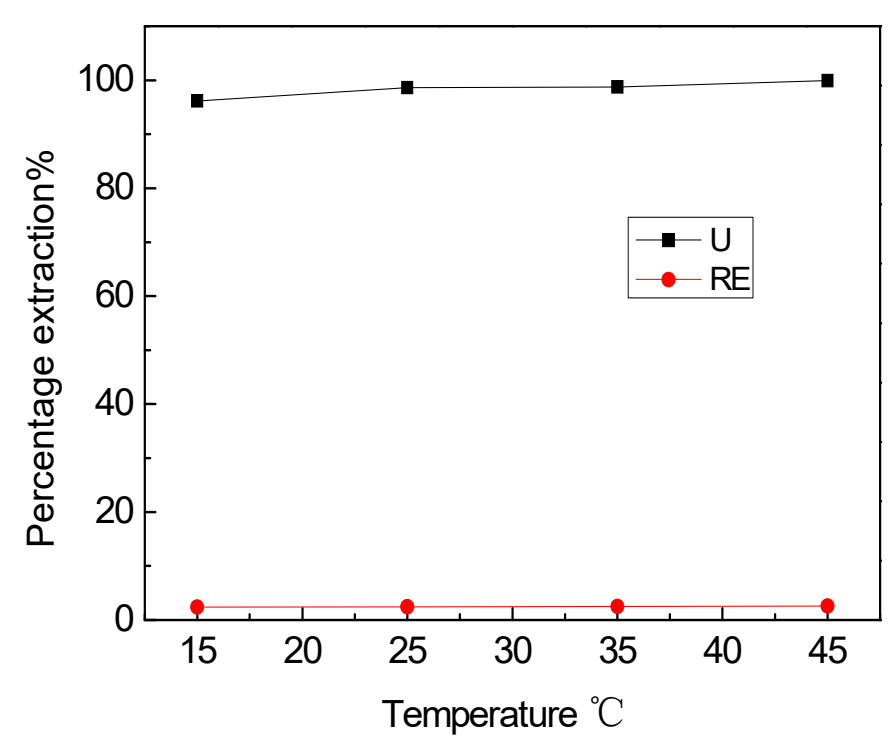

Figure 6. Effect of the temperatures on $\mathrm{U}$ extraction

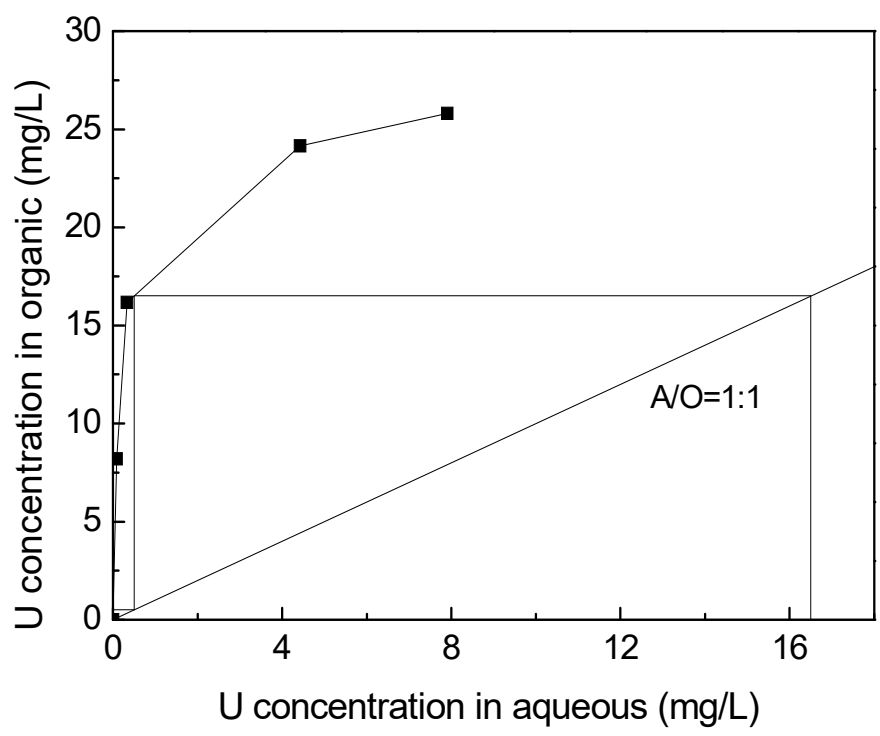

Figure 7. $\mathrm{U}$ extraction distribution isotherm and its McCabe-Thiele diagram.

Table 5. Results of a three-stage counter current extraction test.

\begin{tabular}{ccccc}
\hline Element & $\mathrm{RE}$ & $\mathrm{U}$ & $\mathrm{Fe}$ & $\mathrm{Al}$ \\
\hline Leach liquor & $1.75 \mathrm{~mol} / \mathrm{L}$ & $16.50 \mathrm{mg} / \mathrm{L}$ & $28.00 \mathrm{mg} / \mathrm{L}$ & $2.36 \mathrm{~g} / \mathrm{L}$ \\
Raffinate & $1.72 \mathrm{~mol} / \mathrm{L}$ & $0.05 \mathrm{mg} / \mathrm{L}$ & $9.10 \mathrm{mg} / \mathrm{L}$ & $1.97 \mathrm{~g} / \mathrm{L}$ \\
Extraction (\%) & 1.71 & 99.70 & 67.50 & 16.53 \\
\hline
\end{tabular}




\subsection{Stripping}

\subsubsection{Effect of the $\mathrm{HCl}$ concentration on $\mathrm{U}$ - stripping}

Stripping of the loaded organic solution containing $16.45 \mathrm{mg} / \mathrm{L}$ using $\mathrm{HCl}$ solutions with concentrations ranging from 1.0 to $6.0 \mathrm{~mol} / \mathrm{L}$ at an $\mathrm{A} / \mathrm{O}$ ratio of $1: 1$ at $27 \pm 1^{\circ} \mathrm{C}$ for $10 \mathrm{~min}$ gave the results shown in Figure 8. The stripping of $\mathrm{U}$ increases rapidly from 47 to $99 \%$ at an $\mathrm{HCL}$ concentration of $5.0 \mathrm{~mol} / \mathrm{L}$ and then levels off. Consequently, a concentration of 5 $\mathrm{mol} / \mathrm{L}$ was selected for further operations.

3.2.2 $U$ stripping isotherm and McCabe-Thiele diagram

The isotherm for U-stripping from a loaded organic solution containing 16.45 $\mathrm{mg} / \mathrm{L} \mathrm{U}$ by a strip solution containing 5 $\mathrm{mol} / \mathrm{L} \mathrm{HCl}$ using $\mathrm{A} / \mathrm{O}$ ratios of 1:1, 1:5, 1:10 and $1: 15$ at $27 \pm 1^{\circ} \mathrm{C}$, contacting for $10 \mathrm{~min}$ is shown in Figure 9 together with a McCabe-Thiele diagram. These show that a U--stripping capacity of ca. $180 \mathrm{mg} / \mathrm{L}$ can be obtained using $5 \mathrm{~mol} / \mathrm{L} \mathrm{HCl}$. To ensure that $\mathrm{U}$ is completely stripped, the $\mathrm{A} / \mathrm{O}$ ratio of 1:10. Based on the McCabe-Thiele diagram constructed for the loaded organic solution, two theoretical stripping stages are needed to strip almost all of the $U$ and to leave a few $\mathrm{mg} / \mathrm{L}$ of $\mathrm{U}$ in the organic solution at an $\mathrm{A} / \mathrm{O}$ ratio of 1:10. Assuming that the stage efficiency cannot be $100 \%$, a three-stage counter current extraction system was chosen for the tests described below.

\subsubsection{Three-stage counter current stripping}

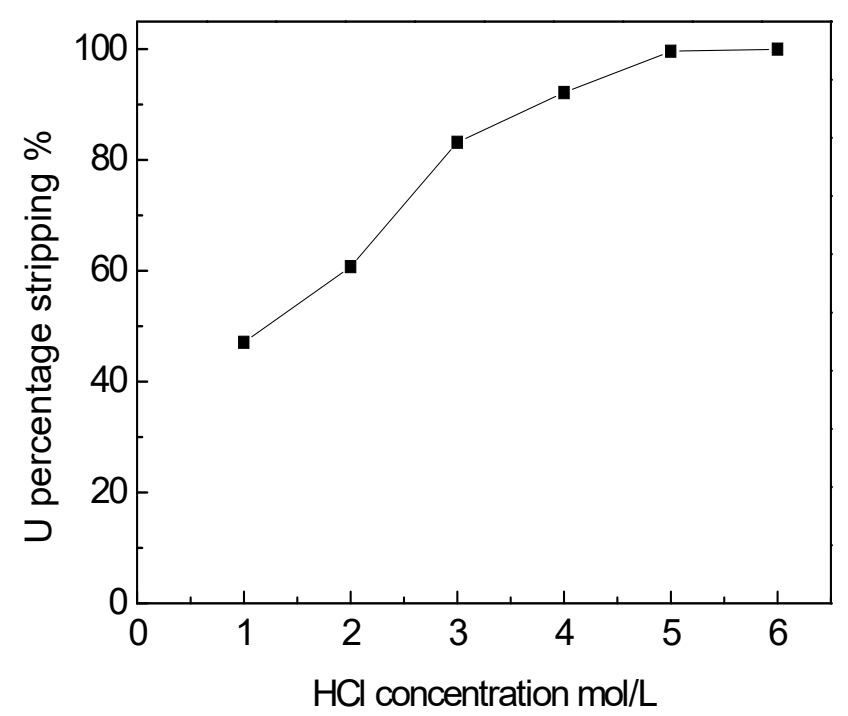

Figure 8. Effect of $\mathrm{HCl}$ concentration on the stripping of $\mathrm{U}$

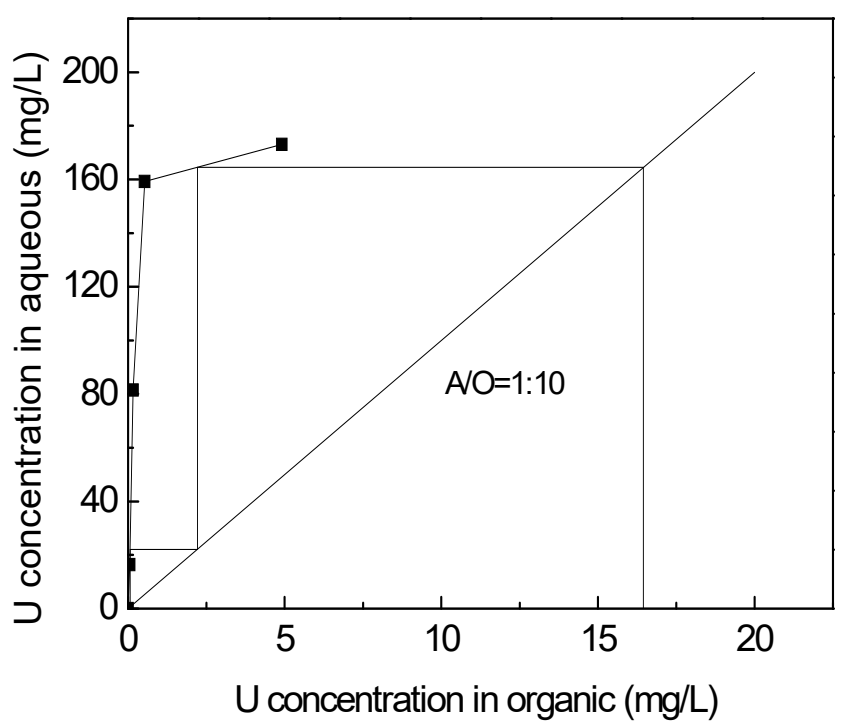

Figure 9. U stripping distribution isotherm and its McCabe-Thiele diagram.

A three-stage counter current stripping test was conducted using the loaded organic solution and a strip solution of $5 \mathrm{~mol} / \mathrm{L} \mathrm{HCl}$ at an $\mathrm{A} / \mathrm{O}$ ratio of $1: 10$ for $10 \mathrm{~min}$ at $27 \pm 1^{\circ} \mathrm{C}$. As can be seen in Table $6, \mathrm{U}$ and other co-extracted metals can be completely stripped using $5 \mathrm{~mol} / \mathrm{L} \mathrm{HCl}$, regenerating the extractant for recycling. The $\mathrm{U}$ in the South China's ion-adsorption RE leach liquor was removed completely and enriched in the strip liquor to $164.50 \mathrm{mg} / \mathrm{L}$. 
Table 6. Test results of three-stage counter current stripping.

\begin{tabular}{ccccc}
\hline Element & RE & $\mathrm{U}$ & $\mathrm{Fe}$ & $\mathrm{Al}$ \\
\hline Loaded organic solution & $0.03 \mathrm{~mol} / \mathrm{L}$ & $16.45 \mathrm{mg} / \mathrm{L}$ & $18.90 \mathrm{mg} / \mathrm{L}$ & $0.39 \mathrm{~g} / \mathrm{L}$ \\
Loaded strip liquor & $0.31 \mathrm{~mol} / \mathrm{L}$ & $164.50 \mathrm{mg} / \mathrm{L}$ & $0.19 \mathrm{~g} / \mathrm{L}$ & $3.91 \mathrm{~g} / \mathrm{L}$ \\
Stripping (\%) & 100 & 100 & 100 & 100 \\
\hline
\end{tabular}

\section{Conclusion}

A naphthenic acid extractant can be used to remove the radionuclide $U$ selectively from South China's ion-adsorption RE leach liquor, thereby achieving a very effective removal of radioactivity and significant environmental benefits. $99.70 \%$ of the $U$ is removed by three-stage counter current extraction using an organic system consisting of $15 \%(\mathrm{v} / \mathrm{v})$ naphthenic acid and $15 \%(\mathrm{v} / \mathrm{v})$ iso-octanol in sulfonated kerosene with an $\mathrm{A} / \mathrm{O}$ ratio of $1: 1$ at $27 \pm 1^{\circ} \mathrm{C} .67 .50 \%$ of the $\mathrm{Fe}$ and $16.53 \%$ of the $\mathrm{Al}$, but only $1.71 \%$ of the $\mathrm{RE}$ are co-extracted. All of the loaded metals can be stripped completely by three-stage counter current stripping using $5 \mathrm{~mol} / \mathrm{L} \mathrm{HCl}$ with an $\mathrm{A} / \mathrm{O}$ ratio of $1: 10$ at $27 \pm 1^{\circ} \mathrm{C}$, regenerate the extractant. The $\mathrm{U}$ removed has a concentration of $164.50 \mathrm{mg} / \mathrm{L}$ in the strip liquor, facilitating radioactive pollution treatment by subsequent precipitation.

\section{Acknowledgements}

The study was funded by National Natural Science Foundation of China (No. 51704081), Guangdong Basic and Applied Basic Research Foundation (2019A1515012173), Science and Technology Planning Project of Meizhou (2019A0102003), Science and Technology Planning Project of Guangdong Province (2016B090931003, 2016B020240004, 2017B090907026, 2017B030314081), and Special Project of Science and Technology Development of "GDAS" (2019GDASYL-0402003, 2019GDASYL-0104021).

\section{References}

1) M. J. Kang, B. E. Han, S. Hahn, Environ. Eng. Res., 7, 149-157 (2002).

2) C. Pawlik, ALTA 2013 U-REE Conference. May 25-June 1, Perth, Western Australia (2013).

3) D. Furfaro, D.G.I. Krebs, ALTA2014 U-RE conference, May 24-31, Perth, Australia (2014).

4) J. Ganser, A. Napier, J. Kyle, D. White, S. Jayasekera, ALTA 2014 U-RE conference, May 24-31, Perth, Australia (2014).

5) G. Lockyer, In: REs North America 2014 Conference, June 11, 2014, New York City, USA (2014).

6) T. E. Amer, W. M. Abdella, G. M. A. Wahab, E. M. El-Sheikh, Int. J. Miner. Process., 125, 106-111 (2013).

7) A. H. Orabi, E.M. El-Sheikh, W.H. Saleh, A.O. Youssef, M.Y. El-Kady, Z.M. Shalaby, J. Radiat. Res. Appl. Sci., 9, 193-206 (2016).

8) A. Schierz, H. Zanker, Environ. Pollut., 157, 1088-1094 (2009).

9) D. Schleuter, A. Günther, S. Paasch, H. Ehrlich, Z. Kljajic, T. Hanke, G. Bernhard, E. Brunner, Carbohydr. Polym., 92, 712-718 (2013).

10) M. K. Sureshkumar, D. Das, M. B. Mallia, P. C. Guptaa, J. Hazard. Mater., 184, 65-72 (2010).

11) Z. Zhu, Y. Pranolo, C. Cheng, Miner. Eng., 77, 185-196 (2015).

12) J. C. B. S. Amaral, C. A. Morais, Miner. Eng., 23, 498-503 (2010). 
13) H. N. Hu, Rare Metals and Cemented Carbides, 124, 4-7 (1996).

14) Z. Zhu, C. Cheng, ALTA 2011 U Conference, May 26-27. Burswood Convention Centre, Perth, Australia (2011).

15) C. K. Gupta, B. P. Malik, A. Deep, J. Radioanal. Nucl. Chem., 251, 451-456 (2002).

16) R. Li, H. Zhao, C. Liu, S. He, Z. Li, Q. Li, L. Zhang, Sep. Purif. Technol., 188, 219-227 (2017).

17) Y. Niu, F. Zhao, Z. Shu, H. Zhuang, L. Huang, Y. Zhang, Z. Zhou, J. Nucl. Radiochemistry, 33(3),136-145 (2011).

18) J. E. Quinn, K.H. Soldenhoff, Hydrometallurgy, 152, 7-12 (2015).

19) J. E. Quinn, D. Wilkins, K.H. Soldenhoff, Hydrometallurgy, 134-135, 74-79 (2013).

20) J. Stas, Dahdouh A., H. Shlewit, S. Khorfan, Hydrometallurgy, 65, 23-30 (2002).

21) S. Wu, L. Wang, P. Zhang, H. El-Shall, B. Moudgil, X. Huang, L. Zhao, L. Zhang, Z. Feng, Hydrometallurgy, 175, 109-116 (2018).

22) A. Dartiguelongue, A. Chagnes, E. Provost, W. Fürst, G. Cote, Hydrometallurgy, 165, 57-63 (2016).

23) S. Mondal, V. Kumar, D.K. Singh, J.N. Sharma, T. Sreenivas, V. Kain, Sep. Purif. Technol., 189, 341-346 (2017).

24) G. Xu, Rare Earth, Metallurgical Industry Press, Beijing, China (1995). 